\title{
Global variation in the prevalence and severity of asthma symptoms: Phase Three of the International Study of Asthma and Allergies in Childhood (ISAAC)
}

\author{
C K W Lai, ${ }^{1}$ R Beasley, ${ }^{2}$ J Crane, ${ }^{3}$ S Foliaki, ${ }^{4}$ J Shah, ${ }^{5}$ S Weiland,${ }^{6}$ the ISAAC Phase \\ Three Study Group
}

See Editorial, p 462

- Additional tables and figures are published online only at http://thorax.bmj.com/content/ vol64/issue6

${ }^{1}$ Department of Medicine \& Therapeutics, The Chinese University of Hong Kong, Hong Kong; ${ }^{2}$ Medical Research Institute of New Zealand, Wellington, New Zealand; ${ }^{3}$ Wellington Asthma Research Group, Wellington School of Medicine and Health Sciences, University of Otago, Wellington, New Zealand; ${ }^{4}$ Ministry of Health, Kingdom of Tonga;

${ }^{5}$ Jaslok Hospital \& Research Centre, Mumbai, India;

${ }^{6}$ Department of Epidemiology,

University of Ulm, Ulm, Germany

Correspondence to:

Dr C Lai, Room 1403, Takshing

House, 20 Des Voeux Road

Central, Hong Kong; keilai@

netvigator.com

Dr S Weiland died on 19 March 2007

See the Appendix and Supplementary table S1 for a full list of the members of the ISAAC Phase Three Study Group.

Received 26 August 2008 Accepted 27 January 2009 Published online first

22 February 2009

\begin{abstract}
Background: Phase Three of the International Study of Asthma and Allergies in Childhood (ISAAC) measured the global prevalence and severity of asthma symptoms in children.
\end{abstract}

Methods: A cross-sectional questionnaire survey of 798685 children aged 13-14 years from 233 centres in 97 countries, and 388811 children aged 6-7 years from 144 centres in 61 countries, was conducted between 2000 and 2003 in $>90 \%$ of the centres.

Results: The prevalence of wheeze in the past 12 months (current wheeze) ranged from $0.8 \%$ in Tibet (China) to $32.6 \%$ in Wellington (New Zealand) in the 13-14 year olds, and from $2.4 \%$ in Jodhpur (India) to $37.6 \%$ in Costa Rica in the 6-7 year olds. The prevalence of symptoms of severe asthma, defined as $\geqslant 4$ attacks of wheeze or $\geqslant 1$ night per week sleep disturbance from wheeze or wheeze affecting speech in the past 12 months, ranged from $0.1 \%$ in Pune (India) to $16 \%$ in Costa Rica in the 13-14 year olds and from $0 \%$ to $20.3 \%$ in the same two centres, respectively, in the 6-7 year olds. Ecological economic analyses revealed a significant trend towards a higher prevalence of current wheeze in centres in higher income countries in both age groups, but this trend was reversed for the prevalence of severe symptoms among current wheezers, especially in the older age group.

Conclusion: Wide variations exist in the symptom prevalence of childhood asthma worldwide. Although asthma symptoms tend to be more prevalent in more affluent countries, they appear to be more severe in less affluent countries.

Asthma is one of the most common non-communicable diseases in children. The increase in asthma prevalence in developed countries seen at the end of the last century has raised concern for the considerable burden of this disease on society as well as individuals. Until a decade ago, there were few data on asthma prevalence from developing countries. Recently, the International Study of Asthma and Allergies in Childhood (ISAAC), using a simple and inexpensive standardised methodology, has provided valuable data on the prevalence of the symptoms of childhood asthma, rhinoconjunctivitis and eczema for international comparison from countries with different socio-economic backgrounds. $^{1-3}$

Phase One of this global study was conducted over the early to mid 1990s and involved >700 000 schoolchildren aged 6-7 and 13-14 years from 156 centres in 56 countries. It revealed marked geographic variations in the prevalence of asthma symptoms, even within genetically similar groups. $^{23}$ These findings strongly suggested that environmental factors were likely to be responsible for the observed variations. Phase Three of ISAAC, using the same methodology as Phase One and conducted around the turn of the century, was undertaken to examine time trends in the prevalence of symptoms of asthma and related disorders and to provide more comprehensive information on how the prevalence of these symptoms varies across the world. These time trends data were derived from centres which participated in both phases and have been published elsewhere. ${ }^{4}$ This current paper gives a more comprehensive description of the worldwide prevalence of asthma symptoms, including those which indicate clinically more severe disease, by presenting data not only from centres included in the time trends analysis, but also data from 128 new centres which participated solely in Phase Three. The majority of these new centres were from developing countries in Latin America, Eastern Europe and Africa which have few, if any, epidemiological data on asthma (Supplementary table S1). With the diverse socioeconomic backgrounds of the participating centres, these data are useful not only as a basis for studying the burden of childhood asthma worldwide, but also for exploring the impact of economic development on the prevalence and severity of asthma symptoms.

\section{METHODS}

\section{Study design and questionnaires}

Details of the Phase Three study protocol have been published elsewhere. ${ }^{6}$ This multicountry cross-sectional survey involved schoolchildren of two age groups, 6-7 years and 13-14 years. The study instruments were comprised of a standardised written questionnaire on symptoms of asthma, rhinoconjunctivitis and eczema, and a video questionnaire showing five different scenes of asthma symptoms. ${ }^{7}$ Both questionnaires were self-completed by adolescents in the 13-14 year age group whereas the written questionnaire only was completed by parents of children in the 6-7 year age group. The results for the symptoms of rhinoconjunctivitis and eczema will be reported in separate publications.

In this study, we estimated the prevalence of asthma symptoms based on the responses to (1) the written questionnaire on (a) wheeze in the past 12 months (current wheeze) and (b) frequent or 


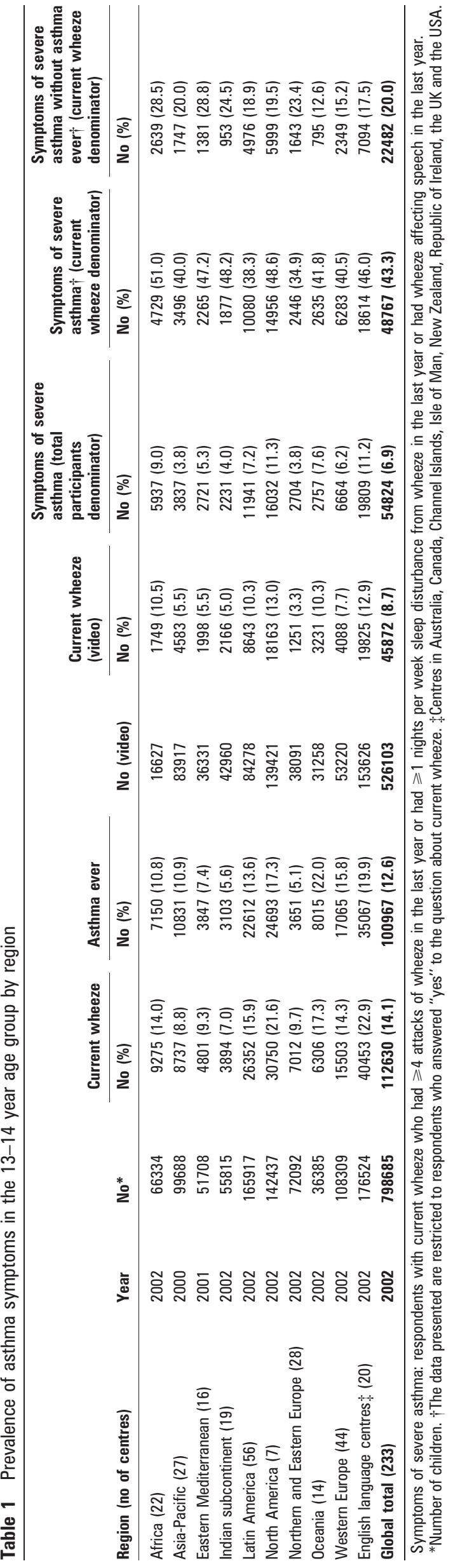

severe episodes of wheeze in the past 12 months (symptoms of severe asthma), and (2) symptoms in the past 12 months reported from the video questionnaire which showed a young person wheezing at rest. Symptoms of severe asthma are defined as those with current wheeze who, according to the written questionnaire, in the past 12 months, have had $\geqslant 4$ attacks of wheeze, or $\geqslant 1$ night per week sleep disturbance from wheeze, or wheeze affecting speech. This definition is based on previous ISAAC analyses that showed a combination of these features of more severe wheezing episodes correlated more closely with asthma mortality and hospital admissions than current wheeze alone. ${ }^{8}$ Reported "asthma ever" was defined from the question "Have you (Has your child) ever had asthma?".

The written questionnaire was translated from English, according to the ISAAC Phase Three protocol, ${ }^{6}$ into one local language in 191 centres (80.3\%), and into more than one in 15 centres $(6.3 \%)$. If any back-translated questions were inaccurate, those questions were not used in the analyses. A total of 54 different languages were used (Supplementary table S1). English and Spanish were the most common languages $(21.0 \%$ and $20.2 \%$ of centres respectively).

\section{Data analysis}

We assessed each centre's adherence to the ISAAC protocol and excluded any with serious discrepancies; minor deviations are noted with footnotes in Supplementary table S1. Response rate was calculated by the number of participants divided by the sum of the total number of eligible children from the participating schools in that centre. Symptom prevalence values in each centre were calculated by dividing the number of positive responses to each question by the number of completed questionnaires for the written and video questionnaires separately. Thus, any apparent inconsistencies between responses to the stem and branch questions were accepted and not recoded. To assess the proportion of children with more severe manifestations of the disease amongst those with asthma symptoms, the number of respondents with severe wheeze was divided by the number of current wheezers derived from the written questionnaire. The kappa statistic was used to examine the relationships between the written and video questionnaire in the 13-14 year age group. An ecological economic analysis was performed to examine the effect of economic development on the prevalence of asthma symptoms. This analysis used a generalised linear mixed model with a logit link and the centre as a random effect to examine the association between countrylevel gross national income (GNI) and the centre-level symptom data. The GNI data were categorised into low, middle and high based on World Bank cut-off values for 2001. ${ }^{9}$ The regional analyses were based on the standard ISAAC regions which are broadly the same as the regions defined by the World Health Organization, but we also performed analyses specifically for English language countries (Australia, Canada, Isle of Man, New Zealand and the UK for 6-7 year olds, and Australia, Canada, Channel Islands, Isle of Man, New Zealand, Republic of Ireland, the UK and the USA for the 13-14 year olds). All analyses were carried out using SAS version 9.1. A $p$ value of $<0.05$ was considered significant.

\section{RESULTS}

Altogether 407 data sets from both age groups were received and the data and methodology checks were completed. Of these, 30 were excluded due to low response rates (16 data sets), $<1000$ 
participants (12) or an inability to calculate a response rate (2). The remaining 377 data sets comprised 1187496 schoolchildren from 237 centres in 98 countries, of which 128 centres (689 413 participants) in 64 countries (34 new countries) had not undertaken ISAAC Phase Three time trends studies.

\section{The 13-14 year age group}

There were 798685 participants from 233 centres in 97 countries. The overall response rate was $88.1 \%$ (Supplementary table S1). The global average for current wheeze based on the written questionnaire was 14.1\%, ranging from $5.1 \%$ in Northern and Eastern Europe to $22 \%$ in Oceania (table 1). Thirty-five centres $(15 \%)$ had a prevalence of current wheeze $\geqslant 20 \%$ and these were mostly from the English language countries and Latin America. Twenty-two centres (9.4\%) had a prevalence of $<5 \%$ and they were mostly in the Indian subcontinent, Asia-Pacific, Eastern Mediterranean, and Northern and Eastern Europe (fig 1).

Globally, $6.9 \%$ of adolescents had symptoms of severe asthma, ranging from $3.8 \%$ in Asia-Pacific and Northern and Eastern Europe to $11.3 \%$ in North America (table 1). Similar to current wheeze, centres with the highest prevalence of severe asthma symptoms ( $\geqslant 7.5 \%$ ) were mostly found in the English language countries and Latin America, although these also included many centres in Africa. Centres with the lowest prevalence $(<2.5 \%)$ were again located mainly in the Indian subcontinent, Northern and Eastern Europe, Asia-Pacific and the Eastern Mediterranean (fig 2 and Supplementary table 2). However, a different pattern was observed in the proportion of current wheezers with symptoms of severe asthma. Africa (51\%), the Indian subcontinent (48.2\%) and the Eastern Mediterranean $(47.2 \%)$ were ranked higher than English language countries (46\%) and Latin America (38.3\%) (Supplementary fig S1). Globally, $20 \%$ of current wheezers with symptoms of severe asthma did not report "asthma ever". This was more commonly seen in the Eastern Mediterranean (28.8\%), Africa (28.5\%), the Indian subcontinent $(24.5 \%)$ and Northern and Eastern Europe $(23.4 \%)$ than in Asia-Pacific (20\%), Latin America (18.9\%), English language countries (17.5\%) or Western Europe (15.2\%) (table 1 and Supplementary fig S2).

A total of 526103 adolescents from 136 centres in 60 countries completed the video questionnaire. In general, the symptom prevalence rates for current wheeze based on the video questionnaire were lower than those derived from the written questionnaire, and there was a fair agreement between these measures (kappa $=0.39,95 \%$ CI 0.38 to 0.39) (table 1 and Supplementary table S2).

\section{The 6-7 year age group}

There were 388811 participants from 144 centres in 61 countries. The overall response rate was $84.5 \%$ (Supplementary table S1). The mean global prevalence for current wheeze was $11.5 \%$, ranging from $6.8 \%$ in the Indian subcontinent to $21.7 \%$ in Oceania (table 2). Twenty-one centres

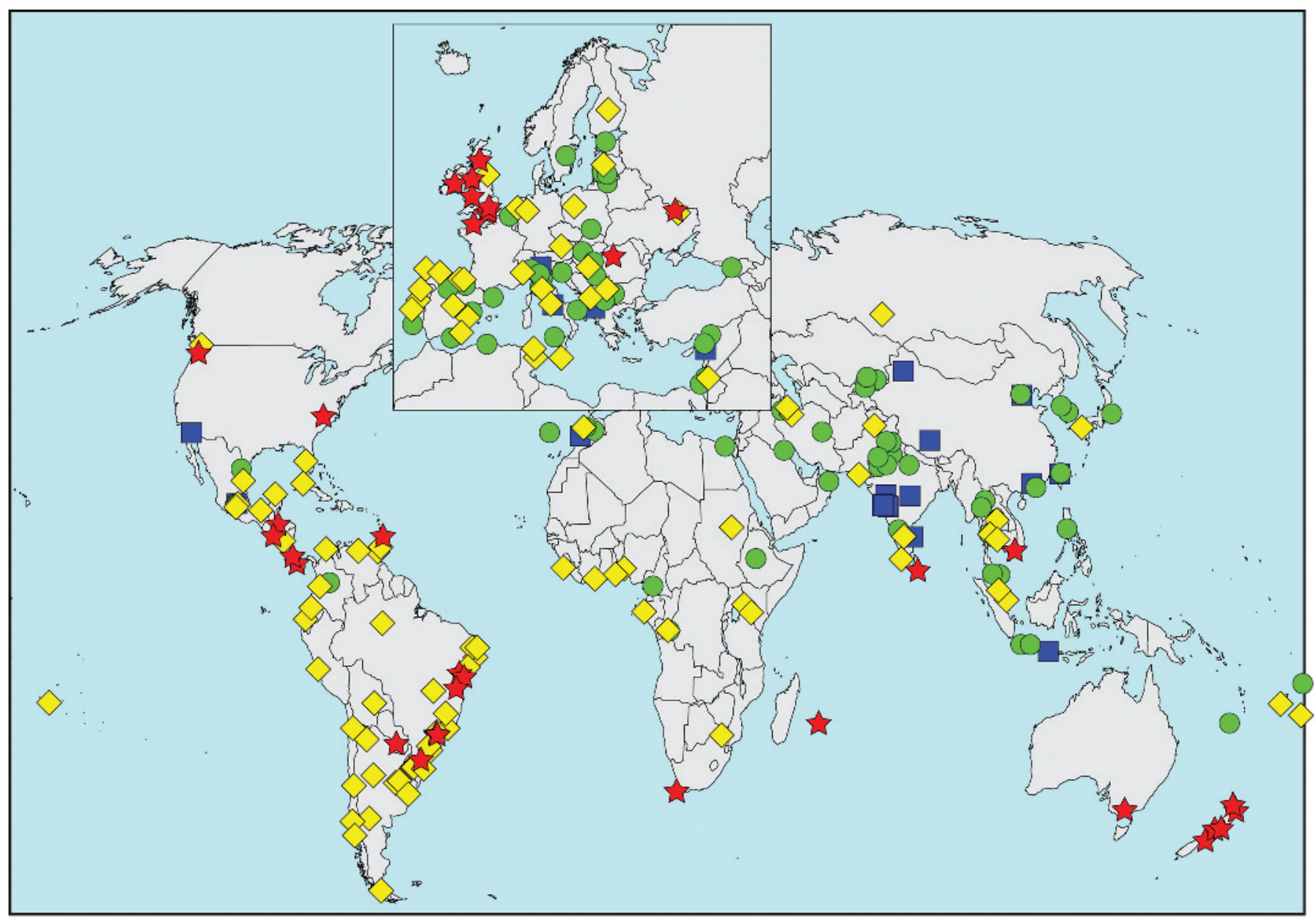

Figure 1 Prevalence of current wheeze according to the written questionnaire in the 13-14 year age group. See text for definition of current wheeze. The symbols indicate prevalence values of $<5 \%$ (blue square), 5 to $<10 \%$ (green circle), 10 to $<20 \%$ (yellow diamond) and $>20 \%$ (red star). 


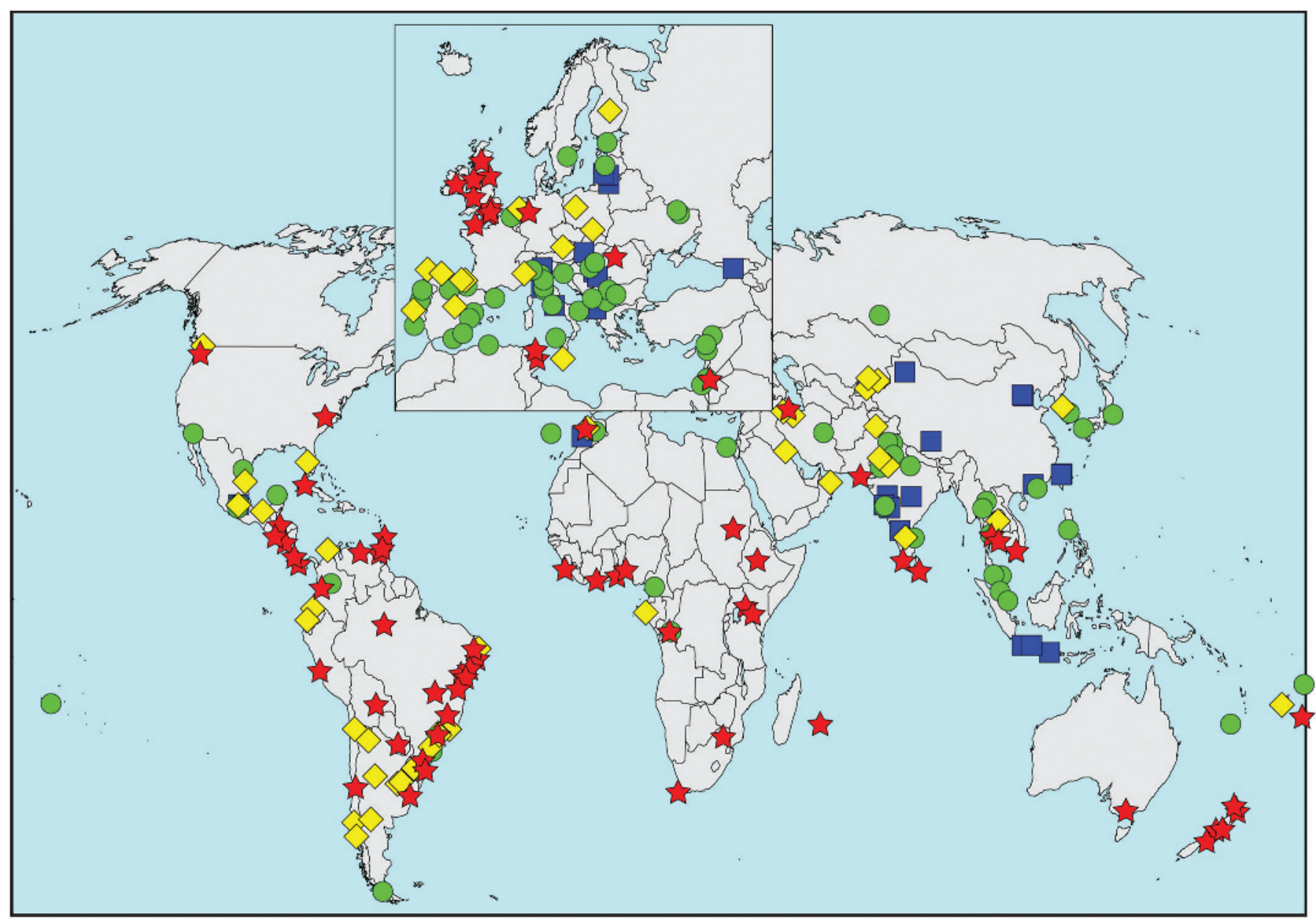

Figure 2 Prevalence of symptoms of severe asthma according to the written questionnaire in the 13-14 year age group. See text for definition of symptoms of severe asthma. The symbols indicate prevalence values of $<2.5 \%$ (blue square), 2.5 to $<5 \%$ (green circle), 5 to $<7.5 \%$ (yellow diamond) and $>7.5 \%$ (red star).

$(14.6 \%)$ had a prevalence of current wheeze $\geqslant 20 \%$, and all but two were in English language countries or Latin America. Seventeen centres $(11.8 \%)$ had a prevalence of $<5 \%$, and these were mostly from the Indian subcontinent, Asia-Pacific and Northern and Eastern Europe (fig 3 and Supplementary table S3).

There were $4.9 \%$ of children worldwide with symptoms of severe asthma, ranging from $3.2 \%$ in Asia-Pacific and Northern and Eastern Europe to $9.5 \%$ in Oceania (table 2). Centres with high prevalence $(\geqslant 7.5 \%)$ were mostly found in Latin America and English language countries, whereas most of the low prevalence $(<2.5 \%)$ centres were from the Indian subcontinent, Asia-Pacific and Northern and Eastern Europe (fig 4). However, centres with a high proportion of current wheezers with symptoms of severe asthma ( $\geqslant 50 \%$ ) were mostly seen in the Indian subcontinent, Eastern Mediterranean, Africa and Latin America. Those with a low proportion $(<30 \%)$ were mostly from Asia-Pacific and Northern and Eastern Europe (Supplementary fig S3). Globally, 16.5\% of current wheezers with severe asthma symptoms had never received a diagnosis of asthma. Undiagnosed asthma amongst these subjects was highest in Africa (40.2\%) and lowest in English language countries (5.8\%) (table 2 and Supplementary fig S4).

\section{Associations with GNI}

Centres in lower income countries tended to have lower prevalence of current wheeze based on the written questionnaire (odds ratios (OR) for low vs high income 0.49 (95\% CI 0.37 to 0.66 ) and 0.55 (0.42 to 0.72 ) for the younger and older age groups, respectively) as well as reported "asthma ever" (OR 0.29 (0.21 to $0.41)$ and 0.35 (0.27 to 0.46 ) for the younger and older age groups, respectively) in both age groups. While the same trend was seen with symptoms of severe asthma in the younger age group (OR $0.61(0.42$ to 0.89$))$, this failed to reach statistical significance in the older age group (OR 0.77 (0.58 to 1.02)). However, the trend with GNI was reversed for the prevalence of symptoms of severe asthma among those with current wheeze, although this was only statistically significant in the older age group (OR 1.46 (1.21 to 1.75); OR 1.24 (0.94 to 1.63) for the younger age group). Centres in lower income countries also tended to have a higher proportion of their current wheezers with symptoms of severe asthma who had no reported "asthma ever" (OR 2.1 (1.48 to 2.99) and OR 1.90 (1.53 to 2.35) for the younger and older age groups, respectively).

\section{DISCUSSION}

The ISAAC Phase Three study, with its much greater number of schoolchildren, participating centres and countries than those of Phase One, has again shown that striking variations in the prevalence of asthma symptoms exist between different geographic areas and populations. Generally, the differences in prevalence between countries were more marked than those within individual countries. There were 13-fold and 9-fold 
Table 2 Prevalence of asthma symptoms in the 6-7 year age group by region

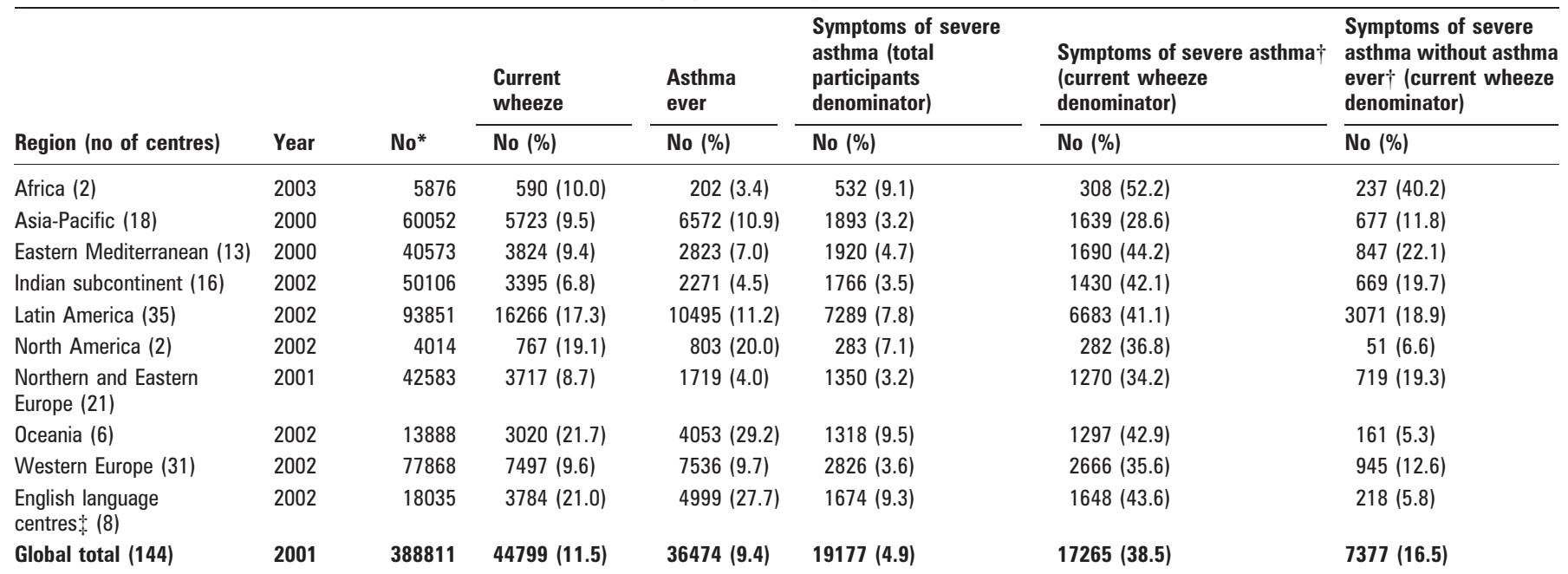

Symptoms of severe asthma: respondents with current wheeze who had $\geqslant 4$ attacks of wheeze in the last year or had $\geqslant 1$ nights per week sleep disturbance from wheeze in the last year or had wheeze affecting speech in the last year.

*Number of children. $\dagger$ The data presented are restricted to respondents who answered "yes" to the question about current wheeze. $₫$ Centres in Australia, Canada, Isle of Man, New Zealand and the UK.

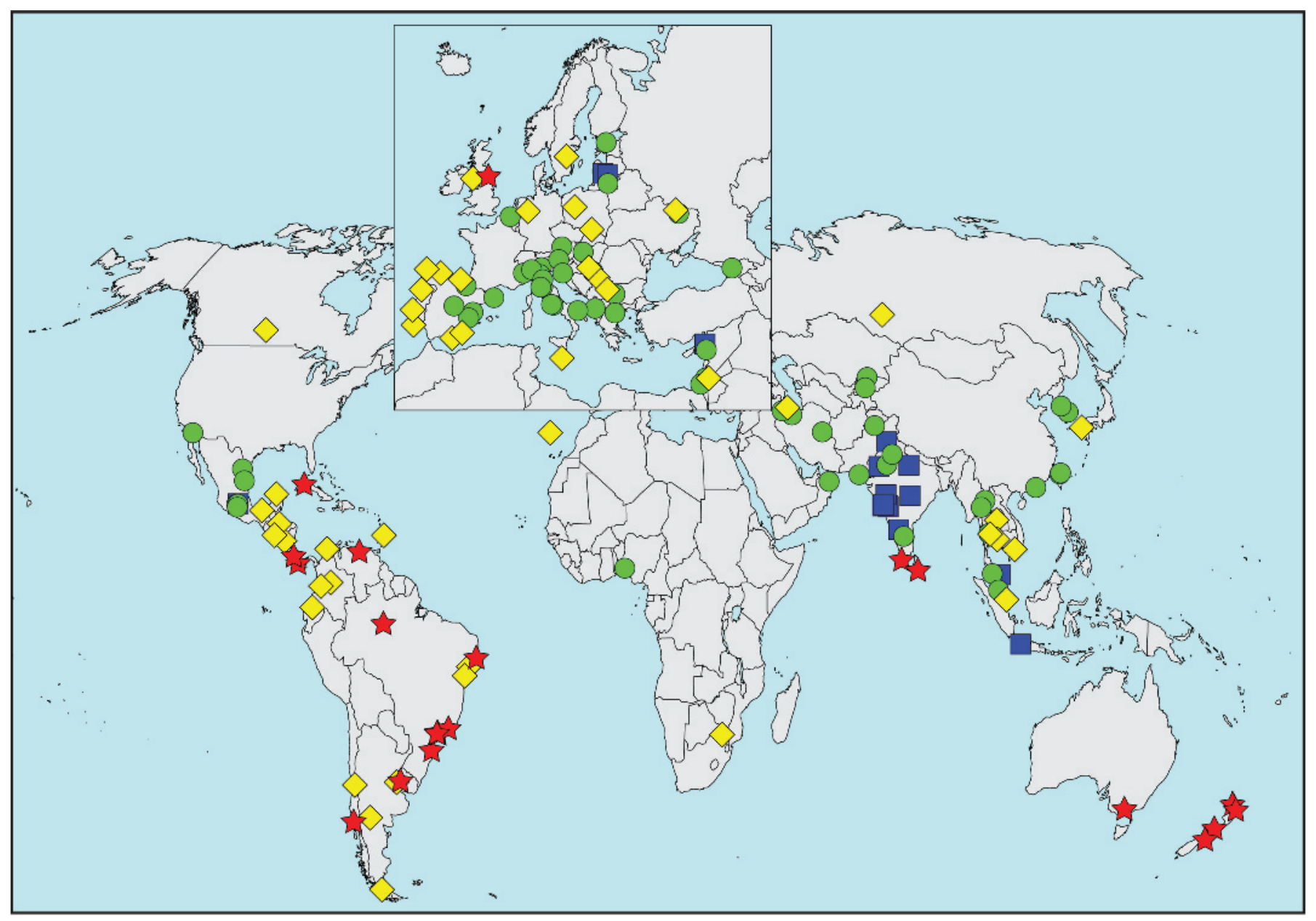

Figure 3 Prevalence of current wheeze in the 6-7 year age group. See text for definition of current wheeze. The symbols indicate prevalence values of $<5 \%$ (blue square), 5 to $<10 \%$ (green circle), 10 to $<20 \%$ (yellow diamond) and $>20 \%$ (red star). 


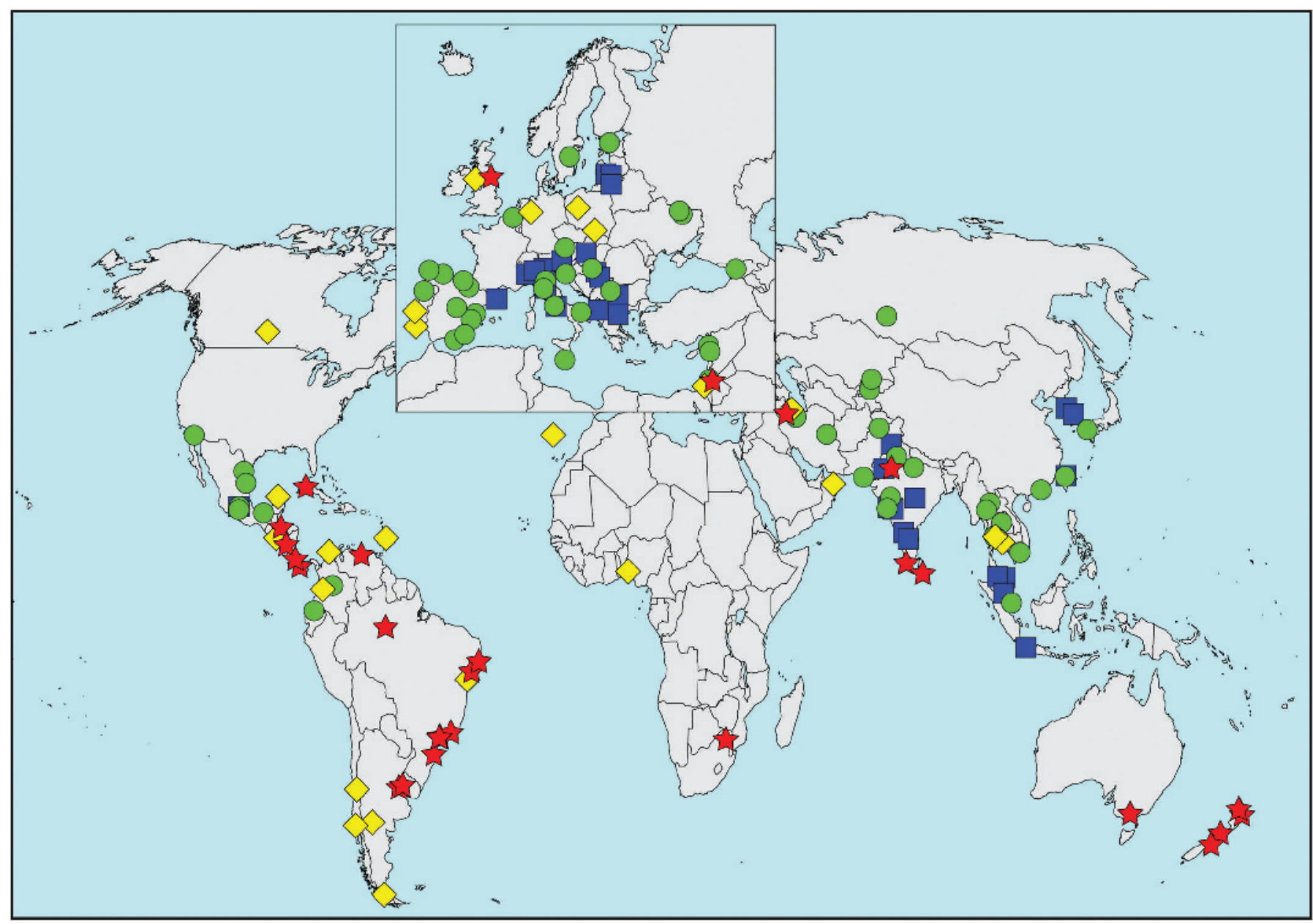

Figure 4 Prevalence of symptoms of severe asthma in the 6-7 year age group. See text for definition of symptoms of severe asthma. The symbols indicate prevalence values of $<2.5 \%$ (blue square), 2.5 to $<5 \%$ (green circle), 5 to $<7.5 \%$ (yellow diamond) and $>7.5 \%$ (red star).

differences between countries with the highest (Costa Rica $37.6 \%$ and Isle of Man 31.2\%) and lowest (Indonesia 2.8\% and Albania $3.4 \%$ ) prevalence rates of 12 -month wheeze based on the written questionnaire in the 6-7 year and 13-14 year age groups, respectively. The intercentre variations were even bigger, ranging from from $2.4 \%$ in Jodhpur (India) to $37.6 \%$ in Costa Rica in the 6-7 year age group and from $0.8 \%$ in Tibet (China) to $32.6 \%$ in Wellington (New Zealand) in the 13-14 year age group. The intercountry variations are also large for the prevalence of symptoms of severe asthma, ranging from $1.1 \%$ in Indonesia to $20.3 \%$ in Costa Rica in the 6-7 year olds, and from $1.1 \%$ in Albania to $16 \%$ in Costa Rica in the $13-14$ year olds. At the centre level, the values ranged from $0 \%$ in Pune (India) to $20.3 \%$ in Costa Rica in the older age group and from $0.1 \%$ to $16 \%$ in the two respective centres in the younger age group (Supplementary tables S2, S3).

While the clinical significance of having only one wheezing episode in a year is questionable, the occurrence of frequent, sleep-disturbing or speech-limiting attacks is widely accepted as clinically important. The latter two symptoms, in particular, are highly specific for bronchial hyper-responsiveness to methacholine. ${ }^{7}$ Furthermore, the prevalence of symptoms of severe asthma, defined in the same way as the current study, has been shown to correlate more strongly than that of current wheeze with national asthma hospitalisation and mortality rates in both age groups. ${ }^{8}$ Severe or frequent symptoms are also less likely to go unnoticed by subjects who have no family history of asthma and come from deprived family backgrounds, ${ }^{10}$ such as those in the developing countries. The prevalence rates of symptoms of severe asthma can therefore be justifiably used as surrogates of disease burden, especially in areas where data on healthcare utilisation and mortality are unavailable. The standardised way in which the study was conducted, as well as its high response and participation rates, also makes these data useful for comparisons of asthma burden between different populations and time points.

The international patterns of severe wheeze are in accord with those seen for current wheeze in both age groups-that is, the highest ranked centres were mostly from the English language countries and Latin America, and the lowest ranked ones were mainly found in the Indian subcontinent, AsiaPacific, the Eastern Mediterranean, and Northern and Eastern Europe. Africa, however, had proportionally more centres with a high prevalence of severe asthma symptoms than for current wheeze. The proportion of current wheezers with severe asthma symptoms was higher in Africa, the Indian subcontinent and the Eastern Mediterranean than in the English language countries for both age groups. This suggests that the disease may be clinically more severe in these less affluent countries than the more affluent English language countries, although the latter have amongst the highest symptom prevalence of asthma worldwide. Ecological economic analyses also revealed that although the high-income centres tended to have a higher prevalence of current wheeze, a reverse trend was 
found in the prevalence of symptoms of severe asthma among current wheezers. There may be several reasons underlying this observation. First, asthma care is likely to be poorer in these developing countries, although a recent epidemiological survey showed that suboptimal asthma management was a global phenomenon. ${ }^{11-13}$ Secondly, there may be less awareness of wheeze being a symptom of asthma, even in those with frequent wheezing, similar to the situation amongst ethnic minorities in developed countries. ${ }^{14}$ This notion is further supported by the finding that undiagnosed asthma among those current wheezers with severe asthma symptoms was most commonly seen in these lower income countries (Supplementary figs S2, S4). Children with undiagnosed frequent symptoms are also more likely to receive inadequate care for their asthma and may fall into a vicious downward spiral of asthma control. ${ }^{14}$ Thirdly, differences in the levels of environmental exposure, including air pollutants and infective agents, may also contribute to the greater severity observed in these countries. These reasons may also explain the observed time trends of asthma prevalence - - that is, prevalence has decreased in previously high prevalence countries, such as the affluent English language countries, but increased in the less affluent developing countries where prevalence was previously low. ${ }^{5}$

ISAAC Phase One revealed high prevalences of reported asthma symptoms in English language countries and Latin America, a higher prevalence in Western Europe than Eastern Europe with a clear Northwest-Southeast gradient, and relatively low prevalences in Africa and Asia. ${ }^{2}{ }^{3}$ The current Phase Three study, with the addition of 128 new centres, confirmed that high prevalence centres were mostly in English language countries and Latin America, as well as confirming the Northwest-Southeast gradient seen in Europe. However, the additional new centres in Africa showed that the prevalence of asthma symptoms in this continent, especially those of severe disease, were one of the highest in the world. While Asia-Pacific and the Indian subcontinent still had many low prevalence centres, new centres such as Ho Chi Minh City (Vietnam) and Sri Lanka were among the highest. Other new centres of interest include Tibet (China), which had the lowest prevalence of current wheeze in the adolescents, and the additional centres in Mexico, which had low prevalence rates in contrast to the generally high rates seen in Latin America. Further studies on these centres of extreme prevalence rates, especially among those of similar ethnic background, may help define the causative factors for asthma. A previous ISAAC Phase Two study on 9- to 10-year-old Chinese schoolchildren in Hong Kong and two cities in mainland China (Guangzhou and Beijing) has shown that the higher prevalence of asthma symptoms in Hong Kong could be explained by differences in environmental factors and diet. ${ }^{15}$

ISAAC phase three has provided the most comprehensive estimate of the worldwide symptom prevalence of asthma to date. This data set comprises centres of different levels of economic development from every continent, including many from developing countries in Africa, Eastern Europe and Latin America where asthma prevalence and severity data, until now, were scant or non-existent. While English language countries and Latin America may have the highest prevalence of asthma, the disease appears to be less often recognised and more severe in Africa, the Indian subcontinent and the Eastern Mediterranean. This global map of asthma is invaluable not only for public health planning, but also for generating hypotheses in explaining the aetiological factors for this common disorder.
Acknowledgements: We are grateful to the children and parents who participated in ISAAC Phase Three, and the coordination and assistance by the school staff is sincerely appreciated. Without their willing cooperation, the extensive worldwide participation of centres involved in ISAAC phase three would not have been possible.

Funding: The ISAAC International Data Centre (IIDC) is funded by the BUPA Foundation, with additional support from the Health Research Council of New Zealand, the Asthma and Respiratory Foundation of New Zealand, the Child Health Research Foundation, the Hawke's Bay Medical Research Foundation, the Waikato Medical Research Foundation, Glaxo Wellcome New Zealand, the NZ Lottery Board and Astra Zeneca New Zealand. Glaxo Wellcome International Medical Affairs supported the regional coordination for Phase Three and the IIDC.

Competing interests: None.

Ethics approval: Centres were expected to obtain ethics approval and parental consent according to the requirements of their country.

\section{REFERENCES}

1. Asher MI, Keil U, Anderson HR, et al. International Study of Asthma and Allergies in Childhood (ISAAC): rationale and methods. Eur Respir J 1995;8:483-91.

2. The International Study of Asthma and Allergies in Childhood (ISAAC) Steering Committee. Worldwide variation in prevalence of asthma, allergic rhinoconjunctivitis, and atopic eczema: ISAAC. Lancet 1998;351:1225-32.

3. ISAAC Steering Committee. Worldwide variations in the prevalence of asthma symptoms: the International Study of Asthma and Allergies in Childhood (ISAAC). Eur Respir J 1998;12:315-35.

4. Asher MI, Montefort S, Björkstén B, et al. Worldwide time trends in the prevalence of symptoms of asthma, allergic rhinoconjunctivitis, and eczema in childhood: ISAAC phases one and three repeat multicountry cross-sectional surveys. Lancet 2006;368:733-43.

5. Pearce N, Aït-Khaled N, Beasley R, et al. Worldwide trends in the prevalence of asthma symptoms: phase III of the International Study of Asthma and Allergies in Childhood (ISAAC). Thorax 2007;62:758-66.

6. Ellwood P, Asher MI, Beasley R, et al. The International Study of Asthma and Allergies in Childhood (ISAAC): Phase Three rationale and methods. Int J Tuberc Lung Dis 2005;9:10-16.

7. Lai CKW, Chan JKW, Chan A, et al. Comparison of the ISAAC video questionnaire (AVO 3.0) with the ISAAC written questionnaire for estimating asthma associated with bronchial hyperreactivity. Clin Exp Allergy 1997;27:540-45.

8. Anderson HR, Gupta R, Kapetanakis V, et al. International correlations between indicators of prevalence, hospital admissions and mortality for asthma in children. Int J Epidemiol 2008;37:573-82.

9. World Bank. Data for 2001; http://go.worldbank.org/U9BK7IA1J0 laccessed 8 October 2007).

10. Michel G, Silverman M, Strippoli MPF, et al. Parental understanding of wheeze and its impact on asthma prevalence estimates. Eur Respir J 2006;28:1124-30

11. Lai CKW, de Guia TS, Kim YY, et al. Asthma control in the Asia-Pacific region: the Asthma Insights and Reality in Asia-Pacific Study. J Allergy Clin Immunol 2003:111:263-8.

12. Rabe KF, Adachi M, Lai CKW, et al. Worldwide severity and control of asthma in children and adults: the global asthma insights and reality surveys. J Allergy Clin Immunol 2004;114:40-7.

13. Cazzoletti L, Marcon A, Janson C, et al. Asthma control in Europe: a real-world evaluation based on an international population-based study. J Allergy Clin Immunol 2007:120:1360-7.

14. Yeatts K, Davis KJ, Sotir M, et al. Who gets diagnosed with asthma? Frequent wheeze among adolescents with and without a diagnosis of asthma. Pediatrics 2003;111:1046-54.

15. Wong GWK, Ko FWS, Hui DSC, et al. Factors associated with difference in prevalence of asthma in children from three cities in China: multicentre epidemiological survey. BMJ 2004;329:486-9.

\section{APPENDIX: ISAAC PHASE THREE STUDY GROUP}

ISAAC Steering Committee: N Aït-Khaled* (Union Internationale Contre la Tuberculose et les Maladies Respiratoires, Paris, France); H R Anderson (Department of Public Health Sciences, St Georges, University of London, UK); M I Asher (Department of Paediatrics: Child and Youth Health, Faculty of Medical and Health Sciences, The University of Auckland, New Zealand); R Beasley* (Medical Research Institute of New Zealand, Wellington, New Zealand); B Björkstén* (Institute of Environmental Medicine, Karolinska Institutet, Stockholm, Sweden); B Brunekreef (Institute of Risk Assessment Science, Universiteit Utrecht, The Netherlands); J Crane (Wellington Asthma Research Group, Wellington School of Medicine, New Zealand); P Ellwood (Department of Paediatrics: Child and Youth Health, Faculty of Medical and Health Sciences, The University of Auckland, New Zealand); C Flohr (Centre for Evidence Based Dermatology, University of Nottingham, UK); S Foliaki* (Ministry of Health, Kingdom of Tonga); F Forastiere (Department of Epidemiology, localHealth Authority, Rome, Italy); L García-Marcos (Instituto de Salud Respiratoria, Universidad de Murcia, Spain); U Keil* (Institut für Epidemiologie und Sozialmedizin, Universität Münster, Germany); C K W Lai* (Department of Medicine and Therapeutics, The Chinese University of Hong Kong, Hong Kong); J Mallo* (Department of Respiratory Medicine, University of 
Santiago de Chile, Chile); E A Mitchell (Department of Paediatrics: Child and Youth Health, Faculty of Medical and Health Sciences, The University of Auckland, New Zealand); S Montefort* (Department of Medicine, University of Malta, Malta), J Odhiambo* (Centre Respiratory Diseases Research Unit, Kenya Medical Research Institute, Nairobi, Kenya); N Pearce (Centre for Public Health Research, Massey University, Wellington, New Zealand); C F Robertson (Murdoch Children's Research Institute, Melbourne, Australia); J Shah* (Jaslok Hospital \& Research Centre, Mumbai, India); A W Stewart (Population Health, Faculty of Medical and Health Sciences, The University of Auckland, New Zealand); D Strachan (Department of Public Health Sciences, St Georges, University of London, UK); E von Mutius (Dr von Haunerschen Kinderklinik de Universität München, Germany); S K Weiland (Department of Epidemiology, University of Ulm, Germany); G Weinmayr (Institute of Epidemiology, University of Ulm, Germany); H Williams (Centre for Evidence Based Dermatology, Queen's Medical Centre, University Hospital, Nottingham, UK); G Wong (Department of Paediatrics, Prince of Wales Hospital, Hong Kong, SAR China).

*Regional Coordinators
ISAAC International Data Centre: M I Asher, T O Clayton, P Ellwood, E A Mitchell, Department of Paediatrics: Child and Youth Health; and A W Stewart, School of Population Health, Faculty of Medical and Health Sciences, The University of Auckland, New Zealand.

ISAAC Phase Three National Coordinators not identified in Supplementary table S1: Canada, Professor Malcolm Sears; Channel Islands, Professor Ross Anderson; Chile, Dr Viviana Aguirre; Columbia (interim), Professor Javier Mallol; Croatia, Professor Vladimir Ahel; Greece, Associate Professor Christina Gratziou; Hong Kong, Dr Christopher Lai; India, Dr Jayant Shah; Indonesia, Professor Karnen Baratawidjaja; Isle of Man, Professor Ross Anderson; Japan, Professor Sankei Nishima; Kingdom of Tonga, Dr Toakase Fakakovi; The Netherlands, Dr Roy Otten; Nouvelle Caledonie, Dr Sylvie Barny; Polynesie Francaise, Dr René Chansin; Republic of Ireland, Dr Patrick Manning; Republique Democratique du Congo, Dr Etienne Bahati; Russia, Professor Rakhim M Khaitov; Samoa, Dr Nuualofa Tuuau-Potoi; Singapore, Professor Beewah Lee; Sudan, Dr Asma El Sony; Sweden, Dr Lennart Nilsson.

\section{An unusual case of dyspnoea}

\section{CLINICAL PRESENTATION}

A 66-year-old woman presented with progressive exertional dyspnoea, productive cough and dysphonia, particularly when singing; she also experienced a dry obstructed nose, sore mouth and mild dysphagia. She had previously been diagnosed with autoimmune disease affecting her eyes, nasal passages, oropharynx and oesophagus, for which she had received treatment with prednisolone and cyclophosphamide. Immunosuppression continued with azathioprine. She also suffered from aortic stenosis and hypothyroidism, which was treated with levothyroxine. No perinatal respiratory difficulties were known and she had never been intubated. Despite being a non-smoker, she had had frequent lower respiratory tract infections.

Physical examination showed no additional signs but chest radiography revealed ill-defined consolidation in the right upper lobe. Bronchoscopy was performed to exclude mycobacterial infection and showed an abnormal supraglottic region with a ring-like narrowing with scarring extending posteriorly from fused arytenoids through which the true vocal cords could be seen (fig 1). The laryngeal structures did not collapse with inspiration and movement of the true vocal cords was normal. No associated glottic or subglottic abnormalities were identified.

\section{QUESTION}

What is the abnormality at bronchoscopy and what are the differential diagnoses? What symptoms can arise?

See page 515 .

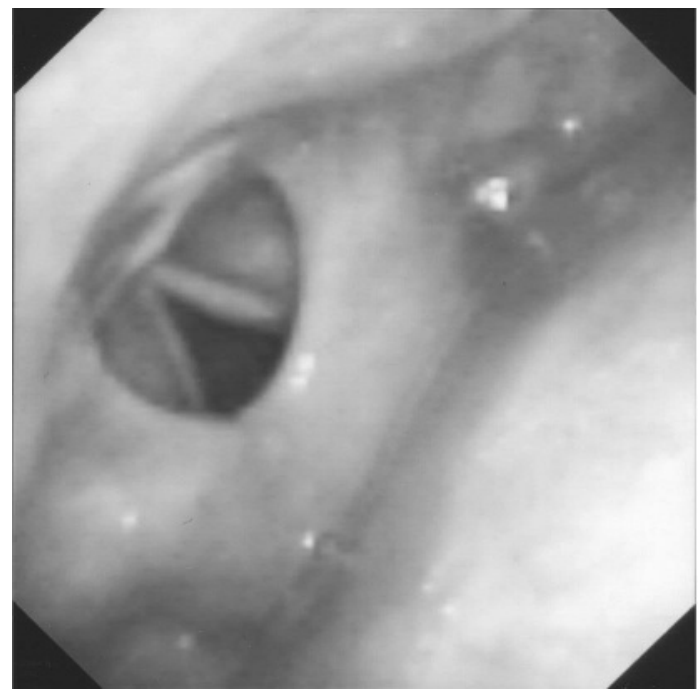

Figure 1 Appearance of supraglottic region at bronchoscopy.

This case was submitted by:

\section{E M Giddings, ${ }^{1}$ M V Holmes, ${ }^{1}$ D Lonsdale, ${ }^{1}$ J Rees, ${ }^{1}$ M J Gleeson ${ }^{2}$}

${ }^{1}$ Department of Respiratory Medicine, Guys and St Thomas' NHS Trust, London, UK;

2Department of Otolaryngology, Guys and St Thomas' NHS Trust, London, UK

Correspondence to: Dr E M Giddings, Department of Respiratory Medicine, Guys and St Thomas' NHS Trust, Lambeth Palace Road, London SE1 7EH, UK; eleanor.Giddings@gstt.nhs.uk

Competing interests: None.

Patient consent: Obtained.

Thorax 2009;64:483. doi:10.1136/thx.2008.101006 